\title{
Effects of the vertical plasma drift velocity on the generation and evolution of equatorial spread $F$
}

\author{
B. G. Fejer, and L. Scherliess \\ Center for Atmospheric and Space Sciences, Utah State University, Logan \\ E. R. de Paula \\ Instituto Nacional de Pesquisas Espaciais, Saõ José dos Campos, Saõ Paulo, Brazil
}

\begin{abstract}
We use radar observations from the Jicamarca Observatory from 1968 to 1992 to study the effects of the $F$ region vertical plasma drift velocity on the generation and evolution of equatorial spread $F$. The dependence of these irregularities on season, solar cycle, and magnetic activity can be explained as resulting from the corresponding effects on the evening and nighttime vertical drifts. In the early night sector, the bottomside of the $F$ layer is almost always unstable. The evolution of the unstable layer is controlled by the history of the vertical drift velocity. When the drift velocities are large enough, the necessary seeding mechanisms for the generation of strong spread $F$ always appear to be present. The threshold drift velocity for the generation of strong early night irregularities increases linearly with solar flux. The geomagnetic control on the generation of spread $F$ is season, solar cycle, and longitude dependent. These effects can be explained by the response of the equatorial vertical drift velocities to magnetospheric and ionospheric disturbance dynamo electric fields. The occurrence of early night spread $F$ decreases significantly during equinox solar maximum magnetically disturbed conditions due to disturbance dynamo electric fields which decrease the upward drift velocities near sunset. The generation of late night spread $F$ requires the reversal of the vertical velocity from downward to upward for periods longer than about half an hour. These irregularities occur most often at $~ 0400$ local time when the prompt penetration and disturbance dynamo vertical drifts have largest amplitudes. The occurrence of late night spread $F$ is highest near solar minimum and decreases with increasing solar activity probably due to the large increase of the nighttime downward drifts with increasing solar flux.
\end{abstract}

\section{Introduction}

Plasma irregularities in the nighttime equatorial $F$ region, generally known as equatorial spread $F$, have been the subject of extensive experimental and theoretical investigations over the last several decades [e.g., Fejer and Kelley, 1980; Kelley, 1989, Fejer, 1996]. These irregularities result from a hierarchy of multistep nonlocal plasma processes involving an interchange instability that includes the collisional and collisionless Rayleigh-Taylor and ExB instabilities and drift waves driven by coupled electrodynamic and neutral atmospheric processes [e.g., Haerendel, 1973; Scannapieco and Ossakow, 1976; Ossakow, 1981; Zalesak et al., 1982; Keskinen et al., 1998, Sekar and Kelley, 1998; Basu and Coppi, 1999].

The association of the rapid postsunset rise of the equatorial $F$ layer with the occurrence of spread $F$ was suggested by the initial observations of these irregularities [Booker and Wells, 1938]. Several studies have shown that the height of the nighttime $F$ layer is the single most important parameter

Copyright 1999 by the American Geophysical Union.

Paper number 1999JA900271.

0148-0227/99/1999JA900271\$09.00 controlling the generation of spread $F$ [e.g., Farley et al., 1970; Ossakow et al., 1979; Rastogi, 1980; Abdu et al., 1983; Sastri, 1984; Kelley and Maruyama, 1992; Jayachandran et al., 1993; Sultan, 1996]. This height is determined largely by the equatorial vertical plasma drift velocity, which is driven by the zonal electric field. The equatorial zonal electric field affects the growth rate of the Rayleigh-Taylor instability through the gravitational and electrodynamic drift terms and by controlling the electron density gradient in the bottomside of the $F$ layer after dusk. In addition, the evening eastward electric field can significantly decrease the $E$ region Pedersen conductivity [Hanson et al., 1986]. Therefore, as suggested by Farley et al. [1970], the equatorial postsunset electric field should play a dominant role on the variability of equatorial spread $F$.

Studies of equatorial spread $F$ using the $50-\mathrm{MHz}$ radar at the Jicamarca Observatory, near Lima, Peru $\left(12^{\circ} \mathrm{S}, 76.9^{\circ} \mathrm{W}\right.$, dip latitude $1^{\circ} \mathrm{N}$ ), have been carried out since the sixties. Farley $e t$ al. [1970] used routine incoherent scatter observations, whereas most of the following studies [e.g., Woodman and LaHoz, 1976; Kelley et al., 1986; Hysell et al., 1990; Farley and Hysell, 1996] relied on measurement techniques especially designed for probing these 3-m irregularities. Recently, Jicamarca spread $F$ studies have used highly improved radar observational techniques [Hysell and Woodman, 1997; Hysell and Burcham, 1998; Kudeki et al., 1999; Kudeki and Bhattacharyya, 1999], and have often been coordinated with 
optical and scintillation measurements [e.g., Basu et al., 1996].

The morphology of equatorial $F$ region plasma drifts has also been extensively studied using Jicamarca radar measurements [e.g., Fejer, 1991, 1997]. These observations have determined the dependence of the $F$ region plasma drifts on season, solar cycle, and magnetic activity. Maruyama [1988] showed that the effect of the vertical drift velocity on the growth rate of the Rayleigh-Taylor instability can explain the winter-summer asymmetry of spread $F$ occurrence over Jicamarca during solar maximum. Kelley and Maruyama [1992] presented case studies of storm-time electric field effects on the generation of equatorial spread $F$ over Jicamarca during postmidnight hours and tested the assumption that the penetration of eastward plasmaspheric electric fields initiates the generation of these irregularities. However, prompt penetration electric fields alone cannot explain the complex dependence of equatorial spread $F$ on magnetic activity [e.g., $F e j e r, 1996]$. In addition, the equatorial vertical drift velocity is strongly affected by both prompt penetration and disturbance dynamo electric fields, and the characteristics of the disturbance electric fields change considerably from premidnight to postmidnight hours [Scherliess and Fejer, 1997; Fejer and Scherliess, 1997].

In this study, we use extensive $F$ region incoherent scatter radar measurements over Jicamarca to examine the effects of quiet-time and disturbance vertical plasma drifts on the generation and evolution of $3-\mathrm{m}$ equatorial $F$ region irregularities for different levels of solar activity. These measurements describe the ambient $F$ region conditions prior to and after the onset of spread $F$ and the evolution of the unstable layers. We will show that our results strongly suggest that the day-to-day, seasonal, and solar cycle variability of spread $F$ occurrence over Jicamarca, and its dependence on magnetic activity can be explained as due mostly to the corresponding variability of the equatorial vertical plasma drifts.

\section{Measurement Techniques and Data}

The results to be presented in this study were obtained using the Jicamarca radar primarily for routine evening and nighttime $F$ region plasma drift measurements. Our database consists of over 200 evening and nighttime periods from April 1968 to March 1992. The experimental procedure for measuring plasma drifts with the Jicamarca radar was described by Woodman [1970]. These observations were typically made over an altitudinal range of $200-600 \mathrm{~km}$, with an altitudinal resolution of $25-40 \mathrm{~km}$, and with an integration time of $\sim 5$ min. The plasma drifts used in our studies correspond to average values generally between $\sim 300-400 \mathrm{~km}$, where the signal-to-noise ratios are greatest. The accuracy of the vertical drift measurements is typically $\sim 1-2 \mathrm{~m} / \mathrm{s}$.

The information on the $F$ region plasma inhomogeneities observed by the Jicamarca radar was obtained using three different sources. From 1968 to 1979 , the presence of spread $F$ was determined mostly from the vertical plasma drift velocity records, as done previously by Farley et al. [1970], who used the 1968-1969 data. From 1969 to 1972, on several occasions, the radar was operated with one half of the antenna pointed perpendicular to the Earth's magnetic field for vertical drift and spread $F$ observations, and the other half was pointed $3^{\circ}$ away from perpendicularity for plasma density and temperature measurements. In this case, electron density profiles were derived from the backscattered power and Faraday rotation, and spread $F$ altitudinal profiles were obtained using the modified range-time-intensity (MRTI) technique [Woodman and LaHoz, 1976]. Plasma density, vertical drift velocity, and spread $F$ data obtained using this technique were presented in a number of studies [Woodman and LaHoz, 1976; Kelley and Maruyama, 1992]. Our most detailed data were obtained from 1980 to March 1992 during a large number of World Day campaigns, which at Jicamarca were dedicated mostly to drift observations. This database consists of altitudinal profiles, usually from $200-600 \mathrm{~km}$, of $F$ region plasma drifts, backscattered power, and pulse-to-pulse correlation normalized to the signal power [e.g., Farley, 1971] for a typical time delay of $5-8 \mathrm{~ms}$. The typical integration time was a few minutes. In the unstable region, these measurements describe the strength and the mean velocity of the plasma irregularities.

The backscattered power from spread $F$ irregularities varies significantly with the level of development of the inhomogeneities, local time, season, solar activity, and with the transmitted power and pulse length. On the other hand, the correlation values from $F$ region irregularities are always noticeably larger than from thermal fluctuations in the incoherent scatter regions, independent from the experimental parameters and geophysical conditions. Therefore it is more practical to determine the height range of the unstable regions using these correlation values. We have used correlation values larger than 0.3 to define the altitudinal range of spread $F$ in the 1980-1992 data. Essentially identical results were obtained for the unstable layer using somewhat larger correlation values or the backscattered power profiles. It is important to note, however, that the relatively large pulse lengths used in the drift experiments result in an overestimate of the vertical thickness of the unstable layers by typically -15-20 km.

\section{Results and Discussion}

In this section, we describe the effects of the vertical plasma drift velocity on the generation and evolution of $F$ region coherent radar backscatter layers over Jicamarca and their dependence on solar and magnetic activity. Since these effects change significantly from early to late night hours, we will consider these two cases separately.

\subsection{Spread F During Premidnight Hours}

Figure 1 shows typical examples of the temporal variation of the vertical drift velocity (positive upward), height of maximum backscattered power from thermal fluctuations $\left(\mathrm{H}_{\mathrm{MP}}\right)$, and spread $F$ layers during equinox low solar flux conditions. The decimetric solar flux indices were about 75 (in units of $10^{-22} \mathrm{Wm}^{-2} \mathrm{~Hz}^{-1}$ ), and the average $K p$ indices were -1.5 . Since the received radar power is inversely proportional to the square of the backscattering altitude, the heights of maximum power are slightly lower than the electron density peak heights. When spread $F$ occurs over a large range of altitudes sampled by the radar, the incoherent scatter technique cannot be used for measuring the ambient plasma drift velocity. Figure 1 illustrates the control of the vertical drift velocity on the height of the $F$ layer after $\sim 1800 \mathrm{LT}$, and on the generation of spread $F$ echoes. The onset of these 


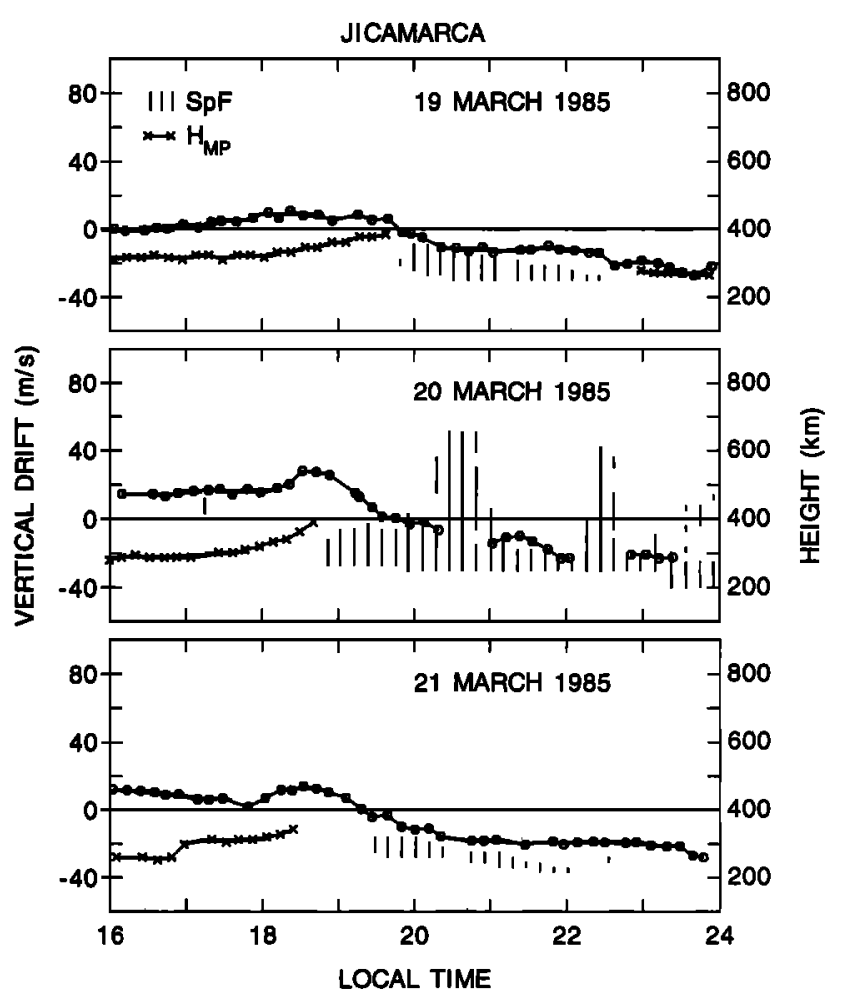

Figure 1. Vertical drift velocities (circles), heights of maximum backscattered power ( $x$ ), and spread $F$ scattering layers (vertical lines) during March 1985. The maximum height probed by the radar was $650 \mathrm{~km}$.

irregularities generally occurs close to the time of reversal of the evening drift velocity when the $F$ layer reaches its highest altitude and the growth rate of the Rayleigh-Taylor instability is maximum. For a given season and solar flux value, larger evening drift velocities lead to the generation of wider and longer lasting regions of strong echoes, which often give rise to radar plumes. The power backscattered from relatively narrow unstable regions below the $F$ region peak, following small evening upward drifts, are significantly smaller (by tens of decibels) than from higher altitude wider scattering layers and radar plumes, which is consistent with results from earlier studies [e.g., Woodman and LaHoz, 1976; Hysell and Burcham, 1998].

Figure 2 presents another set of solar minimum equinoctial radar data. In this case, the daily decimetric solar flux indices were $\sim 80$, and the average $K p$ values were $2.9,2.9$, and 4.5 , respectively. Figure 2 illustrates again the occurrence of broad unstable regions, often covering the entire range of observations, after large upward evening drifts, and the generation of a shorter lived and narrower low altitude unstable layer following smaller upward evening drift velocities. The thickness of thin and low-altitude spread $F$ layers is overestimated in these data owing to the relatively large radar pulse lengths used in the drift experiments. These weak lowaltitude scattering layers are not easily detected using other ground-based techniques. The third panel illustrates the absence of unstable layers associated with an early downward reversal of the vertical drift velocity. The results above support the conclusions of Basu et al. [1996], who suggested that postsunset upward drift velocity enhancements of the

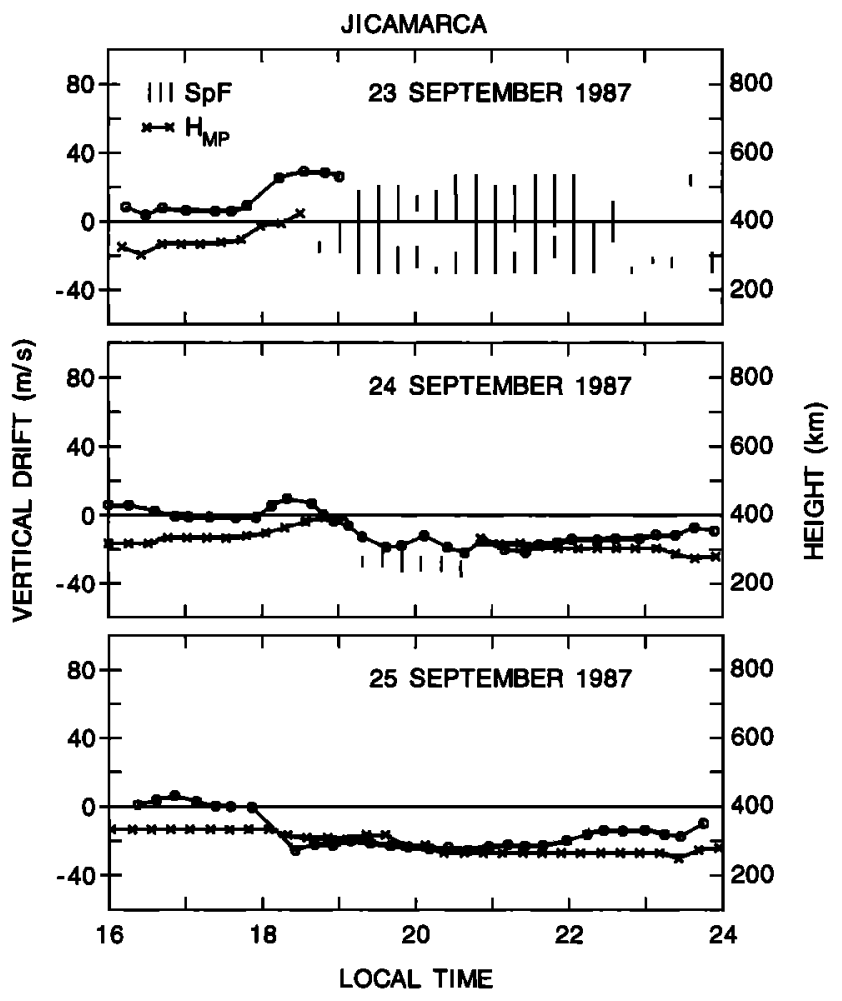

Figure 2. Same as Figure 1, but for September 1987. The maximum height probed by the radar was $550 \mathrm{~km}$.

order of $10-20 \mathrm{~m} / \mathrm{s}$ are necessary for the occurrence of spread $F$ over Peru during equinox solar minimum.

The evening upward drift velocities and the early night $F$ region peak heights increase significantly from solar minimum to solar maximum. Figure 3 shows measurements from equinoctial periods when the solar flux indices were 242 , 275,265 , and 204 , and the average $K p$ values were $1.2,1.2$, 3.1 , and 2.2 , respectively. The two upper panels show relatively broad spread $F$ layers of strong radar backscatter signals, which occasionally reached the highest altitudes sampled by the radar, following very large upward drifts and layer heights. The third panel show a very short lived and very weak (only $\sim 3 \mathrm{~dB}$ stronger than the incoherent scatter signals) at $\sim 2100$ local time, and the fourth panel show no irregularities in spite of the relatively large values of the evening upward drifts.

The results presented above highlight the importance of the evening upward drift velocities on the generation of spread $F$. However, the evolution of the unstable layer can be strongly affected by the drift velocities also after their evening reversal. Figure 4 shows an example of a rapid downward motion and weakening of an unstable layer due to unusually large downward drift velocities driven by westward disturbance electric fields.

We have examined the relationship of the amplitudes of the peak prereversal velocity enhancements and the occurrence of weak and strong spread $F$ echoes in the premidnight sector. Since the backscattered power from the irregularity regions changes noticeably with solar flux due to the change in the ambient plasma density and also with the transmitted power 


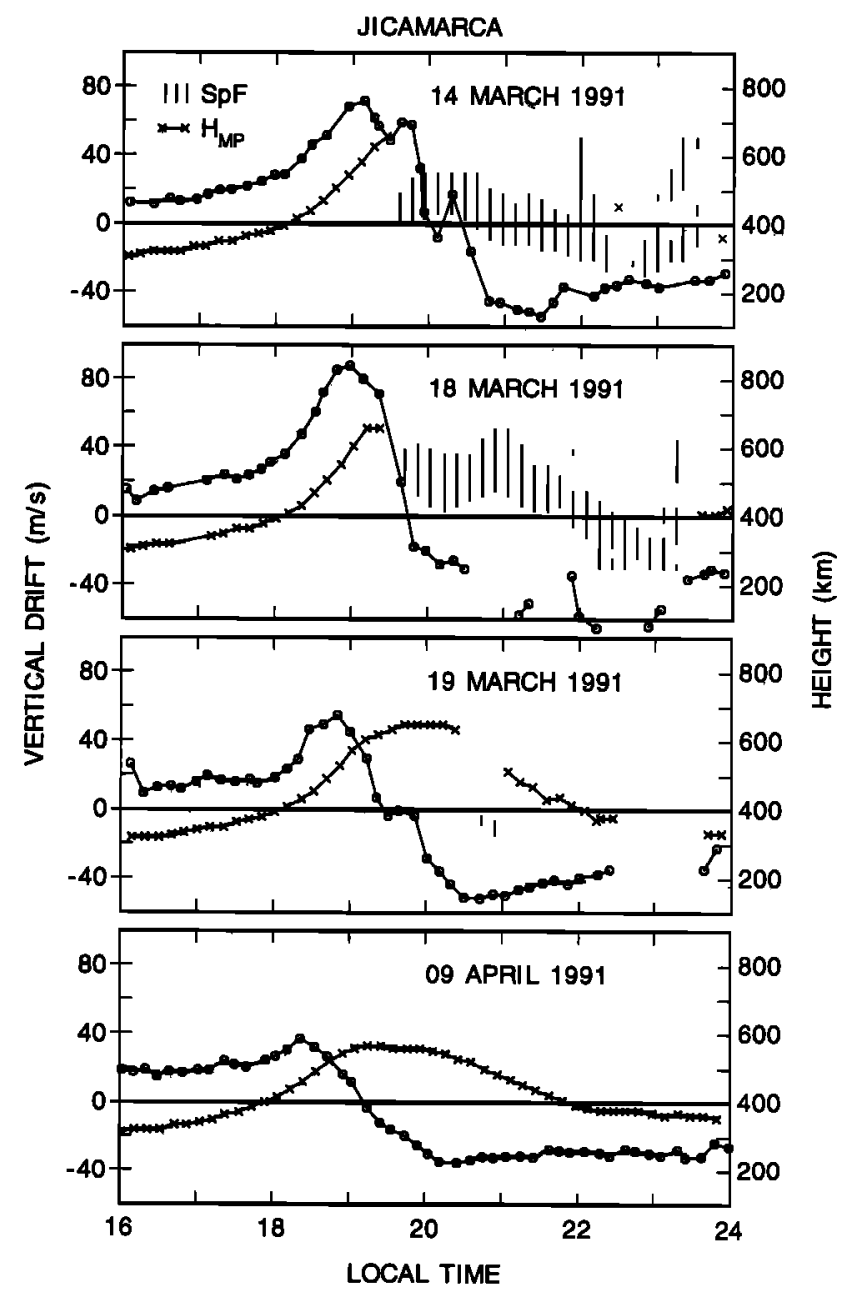

Figure 3. Examples of vertical drift velocities, heights of maximum backscattered power, and spread $F$ scattering layers during equinox solar maximum conditions. The maximum height probed by the radar was $650 \mathrm{~km}$.

and pulse length, we classified the spread $F$ events in terms of the thickness of the unstable layers. Strong radar echoes are always associated with relatively wide scattering layers at higher altitudes, whereas weak echoes correspond to lower altitude and narrow layers [e.g., Woodman and LaHoz, 1976; Hysell and Burcham, 1998]. For the 1980-1992 data, we consider spread $F$ to be strong when the unstable layers cover

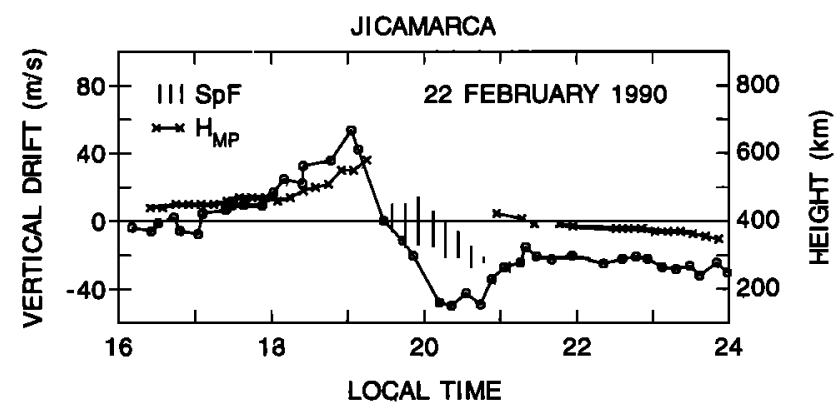

Figure 4. Vertical drift velocities, heights of maximum power, and spread $F$ scattering layer during a disturbed solar maximum period. The $K p$ values were $5^{-}, 5^{-}$, and $3^{-}$, and the decimetric solar flux index was 216. altitudinal ranges in excess of $100 \mathrm{~km}$, which occasionally extend over most of the altitudinal range sampled by the radar. The irregularities in these layers have relatively large eastward drift velocities indicative of dominant $F$ region dynamo effects. These layers correspond essentially to the bottomside layers and plumes studied in detail by Hysell and Burcham [1998]. With this criterion, Figures 1-4 show strong spread $F$ eyents during March 20, 1985, September 23, 1987, and March 14 and 18, 1991. We identify weak spread $F$ with lower altitude and narrower (thickness smaller than $\sim 100 \mathrm{~km}$ ) scattering layers. The irregularities in these layers have either westward or relatively small eastward drift velocities (indicative of relatively strong $E$ region dynamo, or of disturbance dynamo effects) and therefore have generally the characteristics of bottomtype irregularities [Hysell and Burcham, 1998]. For most of the observations before 1980, we do not have detailed information on the strength and/or altitudinal range of spread $F$ echoes. In this case, following Farley et al. [1970], we consider that strong spread $F$ occurs when incoherent scatter drift measurements are not possible owing to these coherent echoes and that normal ambient drift measurements in the presence of coherent echoes are indicative of weak irregularities.

Figure 5 shows the relationship of the amplitudes of the prereversal velocity enhancement and the occurrence of spread $F$. The negative values correspond to downward drifts at the typical times of the prereversal peaks. The evening and early night drift velocities are highly variable near solar minimum. In this case, weak spread $F$ can occur even on nights when the drift velocities are downward near dusk provided that they reverse later to upward drifts for periods longer than about half an hour. Figure 5 shows that equatorial spread $F$ is almost always observed near dusk at all seasons and levels of solar activity and the occurrence of strong scattering layers when the solar cycle dependent evening drift velocities are large enough. This suggests that the seeding mechanisms necessary for the generation of strong irregularities are present essentially all the time. Kudeki and Bhattacharyya [1999] showed that the prereversal velocity enhancement constitutes an important seeding mechanism for the generation of $F$ region irregularities, but there are also other seeding mechanisms such as gravity waves. For a given season and solar flux level, strong echoes are generally associated with larger drift velocities. Over Jicamarca, strong spread $F$ is common between September and April and is rare near June solstice. As the solar flux index increases from 70 to 250 , the threshold velocity for the generation of strong echoes increases from $\sim 5-10 \mathrm{~m} / \mathrm{s}$ to $\sim 50-60 \mathrm{~m} / \mathrm{s}$. This result is consistent with HF Doppler radar and ionosonde measurements from India which showed that the threshold vertical drifts decreased from $\sim 30$ to $-20 \mathrm{~m} / \mathrm{s}$ as the mean decimetric solar flux index changed from 120 to 70 [Jayachandran et al., 1993].

Figure 6 shows the prereversal velocity enhancements and the occurrence of weak and strong spread $F$ following at least 6 hours of magnetically quiet and disturbed conditions. We do not present the results for June solstice since the occurrence of weak spread $F$ does not change much from quiet to disturbed periods, and strong echoes are rarely seen during that season. Figure 6 indicates that during equinox and December solstice quiet time conditions, the $F$ region over Jicamarca is highly unstable during the early night period, with the frequent occurrence of strong spread $F$. The variability of the 

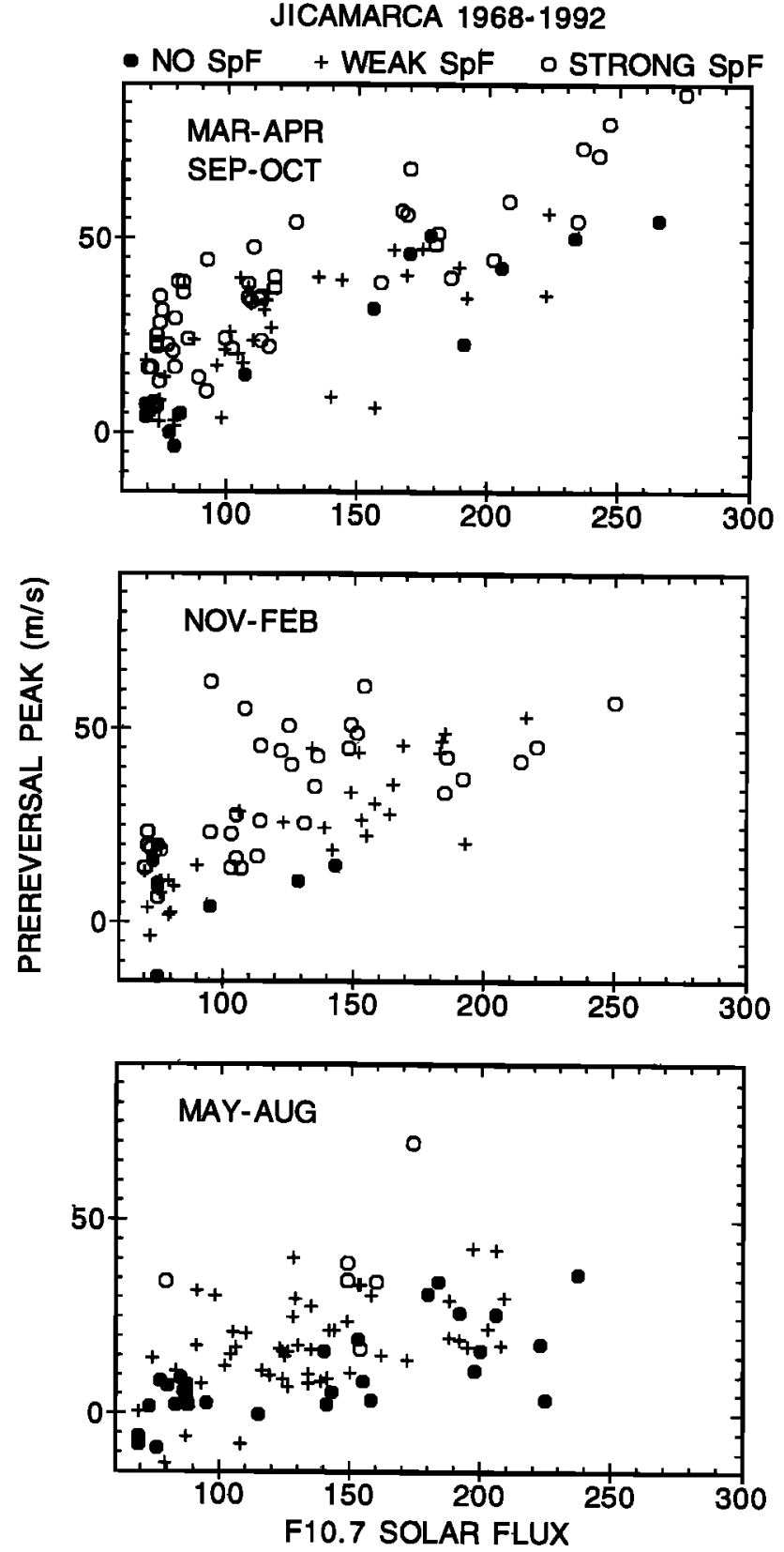

Figure 5. Seasonal and solar cycle dependence of postsunset maximum upward drifts and spread $F$ occurrence.

prereversal velocity enhancements generally decreases with solar activity. Figure 6 shows that sometimes the points of strong and moderate/weak spread $F$ are very close. This is partly due to the fact that the prereversal drift peak does not fully account for the time dependent effect of the vertical drift velocity. In addition, the distinction between moderate and strong spread $F$ is sometimes somewhat subjective. The results for magnetically disturbed periods are discussed below.

The role of the vertical plasma drifts on the generation and evolution of these irregularities can be determined from their effects on the time integrated growth rate of the RayleighTaylor instability [e.g., Maruyama, 1988; Sultan, 1996]. We can estimate these effects by examining the evening and nighttime Jicamarca average quiet time vertical drifts presented in Figure 7. These low and high solar flux curves were obtained by averaging the quiet drift values for $\mathrm{Sa}<80$, and $\mathrm{Sa}>150$, respectively. In this case, the average low solar flux indices were $\sim 75$; the high solar flux values were -195 for June solstice and equinox, and $\mathbf{1 7 4}$ for December solstice. The evening upward and the nighttime downward drifts have small average values and are also highly variable for all seasons near solar minimum [e.g., Fejer, 1981]. In this case, spread $F$ can be easily excited whenever the drift velocities after sunset are upward for periods longer than about half an hour due to either their quiet time variability or to upward disturbance drifts. This is consistent with the occasional occurrence of weak irregularities even when evening drifts are initially downward (see Figure 5) and also with the large range of the onset times of strong spread $F$ near solar minimum [e.g., Hysell and Burcham, 1998].

The evening upward drifts and layer heights increase noticeably with solar activity, but so do the nighttime downward drifts, the ion-neutral collision frequency, and the $F$ layer Pedersen conductivity. Near solar maximum, when the evening upward drifts are large enough, spread $F$ onset typically occurs again near the time of the drift reversal. In this case, however, large downward drifts after sunset rapidly decrease the layer height and the instability growth rates during equinox and June solstice. Therefore the evolution of spread $F$ during these seasons is a race against time where the kilometer scale irregularities in the low-altitude layers need to grow in amplitude, reach the strongly nonlinear regime, and rise into the topside $F$ layer under the effect of internal polarization electric fields, before they are damped as a result of the large downward drifts. Figures 5 and 6 show that the equinoctial upward drifts are generally large enough for exciting strong spread $F$. On the other hand, the small upward drifts and early reversal times during June solstice do not allow for enough wave growth prior to the damping due to the large downward drifts so that the narrow low-altitude unstable layers rarely develop into wide high-altitude strong scattering layers. During December solstice, the large evening upward drifts, the late reversal time, and the small early night downward drifts provide the most favorable conditions for the generation of fully developed strong and longer lasting scattering layers over Jicamarca, as shown earlier by Maruyama [1988]. However, when there are unusually large downward drifts in the early night period (due to westward prompt penetration electric fields, for example) during this season, the unstable layers rapidly weaken and disappear, as illustrated in Figure 4. The results above are fully consistent with the frequency of occurrence of spread $F$ irregularities observed over Jicamarca.

The effect of geomagnetic activity on $F$ region irregularities can be directly related to the response of the equatorial zonal electric field to these disturbances. Several studies have shown that the onset of magnetic activity in the late afternoon increases the occurrence of spread $F$, amplitude scintillations of VHF and UHF beacons, and large-scale plasma depletions in the premidnight sector, while the onset of strong magnetic activity near the noon sector decreases the occurrence of these irregularities and depletions [e.g., Aarons, 1991; Abdu et al., 1995; Sobral et al., 1997; Sahai et al., 1998]. These effects can be explained as due to eastward prompt penetration and westward ionospheric disturbance dynamo electric fields, respectively. The large prereversal velocity enhancement and strong spread $F$ during June solstice (solar flux index of $\sim 170$ ) shown in Figure 5, for example, was associated with a large increase in high-latitude convection near dusk. 


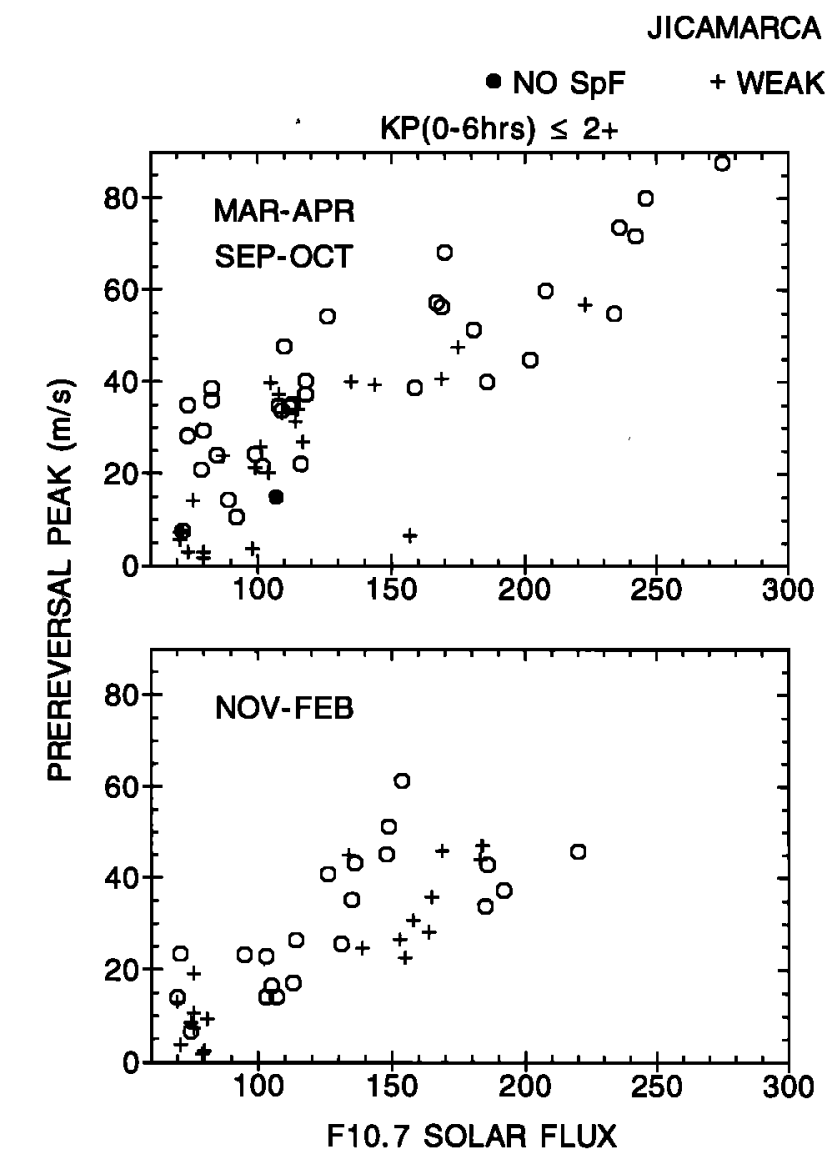

1968-1992

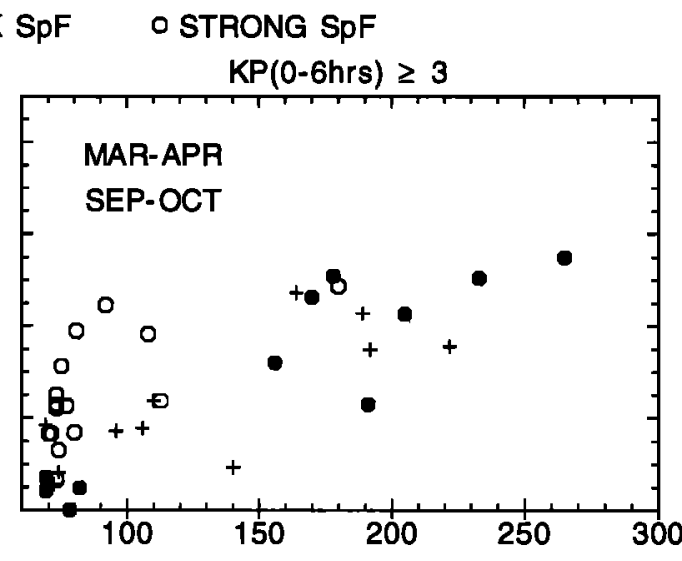

Figure 6. Solar cycle dependence of equinox and December solstice postsunset peak upward drift velocities and spread $F$ for extended magnetic quiet and disturbed periods.

The right-hand panels in Figure 6 show the effects of enhanced magnetic activity over periods of at least 6 hours on the prereversal velocity enhancements and occurrence of spread $F$. This criterion highlights the effect of disturbance dynamo electric fields since prompt penetration electric fields (driven by sudden changes in the high-latitude convection) are equally likely to increase and decrease the evening upward velocities [e.g., Fejer and Scherliess, 1997]. Disturbance dynamo electric fields (driven by enhanced energy deposition into the high-latitude ionosphere) affect the equatorial plasma drifts a few hours after the onset of large auroral disturbances [Scherliess and Fejer, 1997]. Figure 6 indicates that the occurrence of strong spread $F$ is associated with larger upward drifts during disturbed conditions also. Figure 6 suggests that extended magnetic activity during equinox solar maximum conditions generally causes large reductions in the amplitude of the prereversal enhancements, which inhibit the occurrence of spread $F$. Magnetic activity effects are not evident during the solstices, although for December solstice this conclusion is somewhat preliminary since the number of observations during high solar flux disturbed periods in this season is relatively small. As shown earlier, the frequency of occurrence of strong spread $F$ is very small during June solstice.

We examined the seasonal and solar cycle dependence of the evening vertical drifts during extended disturbed conditions in more detail by including additional observations from periods when we do not have sufficient information on the irregularities (e.g., due to data gaps). The results, presented in
Figure 8, confirm that disturbance dynamo electric fields cause large decreases of the evening upward drifts only during equinoctial solar maximum periods. These disturbance dynamo electric fields also explain ionosonde results from Ibadan, Nigeria, which showed a very large decrease of spread $F$ occurrence during disturbed equinoctial periods of very high solar activity in 1959 , but only a small reduction in this occurrence during disturbed summer periods [Lyon et al., $1961]$.

Early night spread $F$ usually disappears within 3-4 hours after onset but sometimes can last well into the late night or even into the early morning hours. Figure 9 shows the seasonal and solar cycle dependence of the long lasting strong spread $F$ events in our database. These events were observed most often near November and during low and moderate solar flux periods. Their shorter life times during periods of high solar activity are probably due to the large increase of the nighttime downward drifts after midnight, as shown in Figure 7. It is interesting to note that Rastogi [1980] reported that the occurrence of range spread $F$ over Huancayo, Peru, has two peaks around November and February during both solar high and low sunspot years and that the probability of postmidnight range spread $F$ is maximum during December solstice low sunspot periods. On the other hand, the percentage of occurrence of $1.5 \mathrm{GHz}$ scintillations over Huancayo show peaks centered around October and March [Basu et al., 1980]. Since the incoherent scatter technique does not provide information on the nighttime electrodynamic 


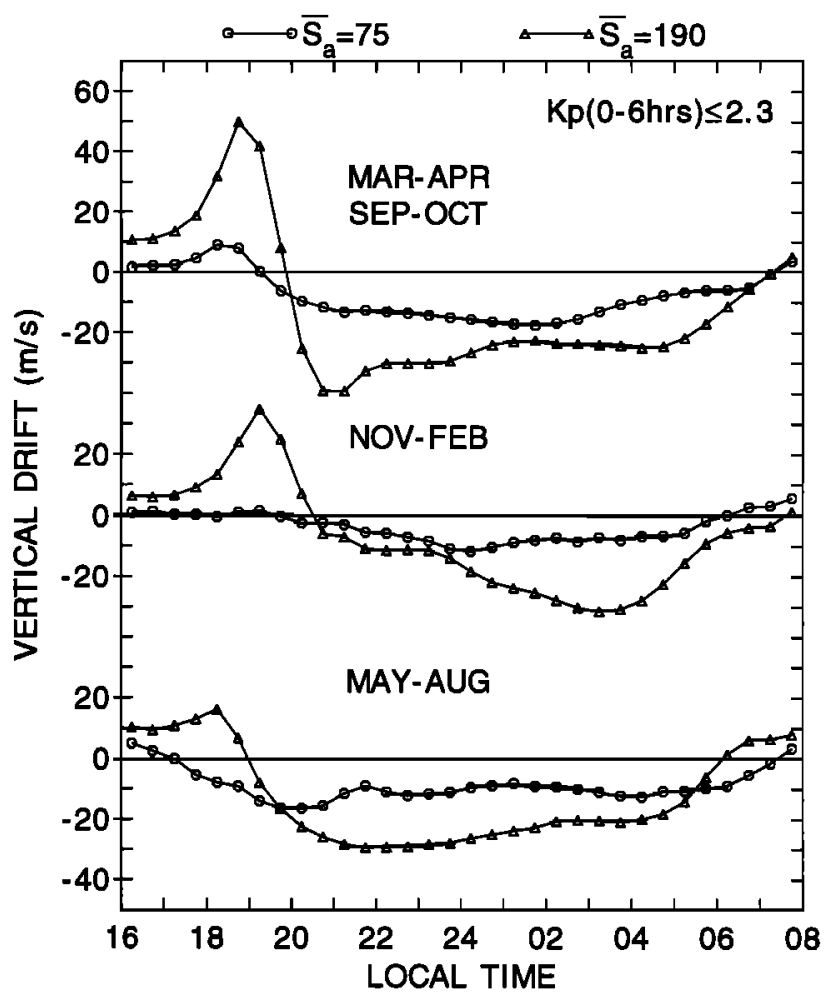

Figure 7. Seasonal variation of the evening and nighttime average vertical drift velocities (positive upward) over Jicamarca during low and high solar flux magnetically quiet conditions.

conditions during these events, we did not study these events in further detail here.

\subsection{Late Night Spread F}

The generation of late night spread $F$ and VHF radio scintillations has long been known to be associated with anomalous reversals of the nighttime drifts from downward to upward generally as a result of eastward disturbance electric fields [e.g., Fejer et al., 1976; Rastogi and Aarons, 1980; Kelley and Maruyama, 1992; Sobral et al., 1997]. These upward drift velocities raise the $F$ layer, make the bottomside to be ExB unstable, and lead to the generation of initially weak plasma irregularities. When the layer is transported to high enough altitudes, the gravitational term becomes dominant resulting in the generation of strong radar echoes and radar plumes [e.g., Kelley and Maruyama, 1992; Hysell and Burcham, 1998].

Figure 10 presents examples of late night vertical drift reversals and spread $F$ development during disturbed equinox solar minimum periods. The top panel shows results from a long period of magnetic activity $\left(K p\right.$ values of $6^{-}, 3,5^{\circ}, 4^{+}$, and 4 ) when downward velocities near dusk inhibited the onset of the instability in the premidnight sector, but large upward disturbance drifts caused the generation of strong postmidnight echoes. The bottom panel shows a moderately wide unstable layer during early night hours and a late night reversal of the vertical velocity with the onset of strong spread $F$ lasting until sunrise. In this case the $K p$ values were $4,3^{+}, 3,2^{-}$, and $2^{+}$. Late night strong spread $F$ is always associated with the occurrence of radar plumes, as illustrated in Figure 10. This is not the case during premidnight hours.

Figure 11 illustrates the season, solar cycle and magnetic activity effects on the generation of late night strong spread $F$. Here the $K p(0-6$ hours $)$ indices denote the average $K p$ values over a 6-hour period prior to the onset of the irregularities, or the average values for the 2200-0400 local time (0300-0900 UT) period when no irregularities were present. In this case, we have not included the late night data if the irregularities were continuously present throughout the entire night (i.e., from the events in Figure 9). The onset of late night strong spread $F$ is most common near solar minimum, particularly during the solstices. MacDougall et al. [1988] showed that during solar minimum the occurrence of presunrise spread $F$ over Fortaleza, Brazil, is also maximum during December solstice. For higher levels of solar activity, our results indicate that strong spread $F$ echoes are observed only during or after increasingly disturbed periods.

The upper panel in Figure 12 gives the relative occurrence of these inhomogeneities as a function of local time for three ranges of the decimetric solar flux index. Late night spread $F$ occurs most often between 0400 and 0600 local time; both the relative occurrence and duration of these events decrease with increasing solar activity. Figure 12 also shows that spread $F$ can occasionally last into the daylight hours. These results are similar to effects of magnetic activity on range spread $F$ and on VHF scintillations from satellite beacons [e.g., Rastogi et al., 1981]. The lower panel in Figure 12 shows the local time dependence of the disturbance drifts following at least 6 hours of disturbed conditions when the average $K p$ value was 2.5 units over our quiet time value $(K p=2)$. As mentioned earlier, these perturbation drifts are driven by ionospheric disturbance dynamo electric fields [Scherliess and Fejer, 1997]. The late nighttime disturbance drifts maximize at $\sim 0400$ local time and do not change much with solar flux, except perhaps near sunrise. The disturbance drifts in the late night sector also appear to be season independent.

Figure 12 indicates that late night spread $F$ occurs most often shortly after the time of largest disturbance dynamo drifts. Prompt penetration eastward (westward) electric fields, due to sudden decreases (increases) in the high-latitude convection drive equatorial nighttime upward (downward) plasma drifts, also have largest amplitudes at $\sim 0400$ local time [Fejer and Scherliess, 1997]. Therefore the most favorable conditions for the generation of late night spread $F$ occur after large and sudden convection decreases when both the prompt penetration and disturbance dynamo electric fields drive large upward drifts. Sudden increases in convection generate westward prompt penetration electric fields in the late night period, which increase the downward drift velocities, decrease the height of the $F$ layer, and further inhibit the generation of irregularities.

Figure 7 shows that the nighttime downward drifts are very small near solar minimum. In this case, the vertical drift velocity can easily be reversed by the disturbance drifts, even in the absence of large prompt penetration electric fields. The nighttime downward drifts increase significantly with solar activity. Under these conditions, the relative absence/infrequent occurrence of strong spread $F$ for large decimetric flux values in Figure 11 shows that increasingly larger upward perturbation drifts are required to overcome the corresponding large downward drift velocities and to move the layer to high enough altitudes for the generation of strong spread $F$. 


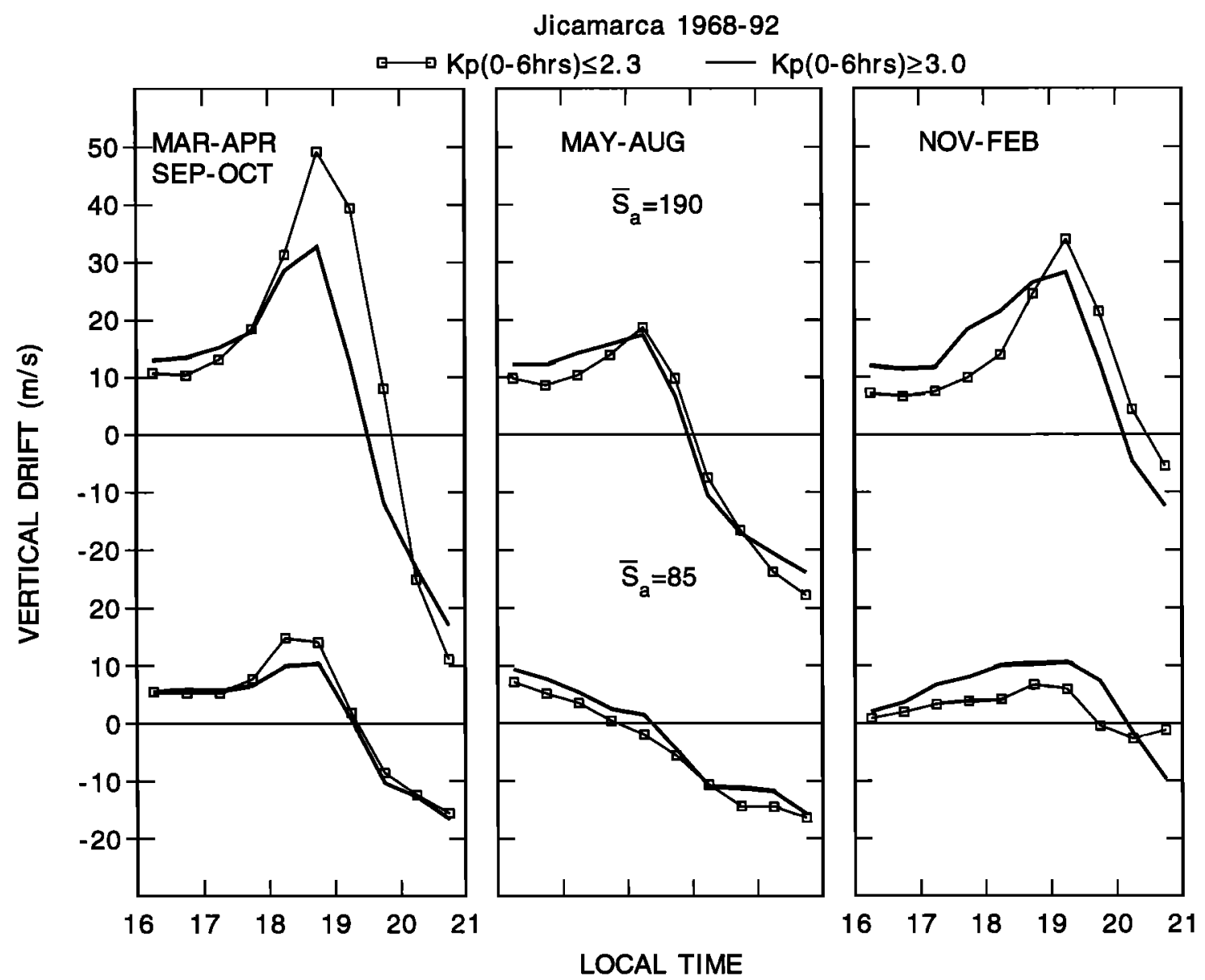

Figure 8. Seasonal variation of quiet time and ionospheric disturbance drift velocities during low and high solar activity periods.

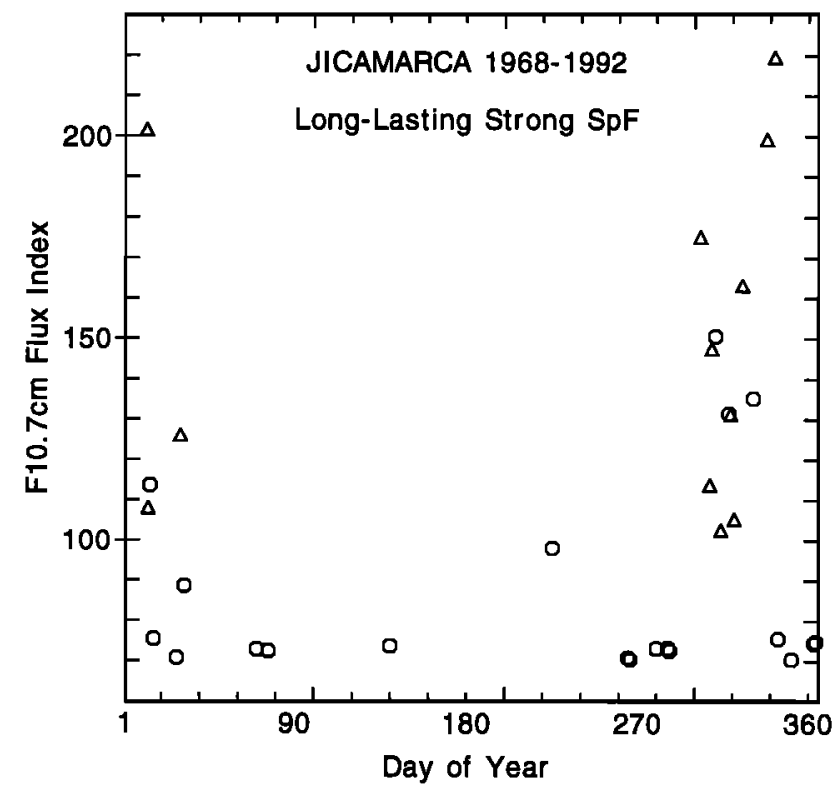

Figure 9. Plot of the annual and solar cycle variations of long lasting strong spread $F$ events. The triangles denote spread $F$ occurrences from shortly after dusk up to $0200-0400$ local time, and the circles indicate events lasting past 0400 local time.

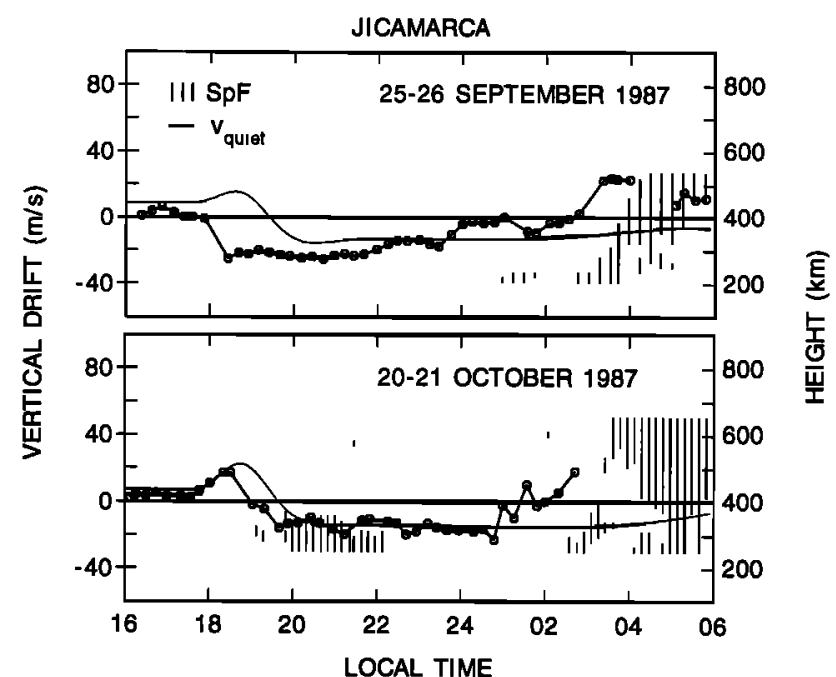

Figure 10. Examples of late night vertical velocity reversals and occurrence of spread $F$ during low solar flux disturbed conditions. The solid curves denote the corresponding average quiet time drift patterns. 
JICAMARCA 1968-1992 23-06 LT
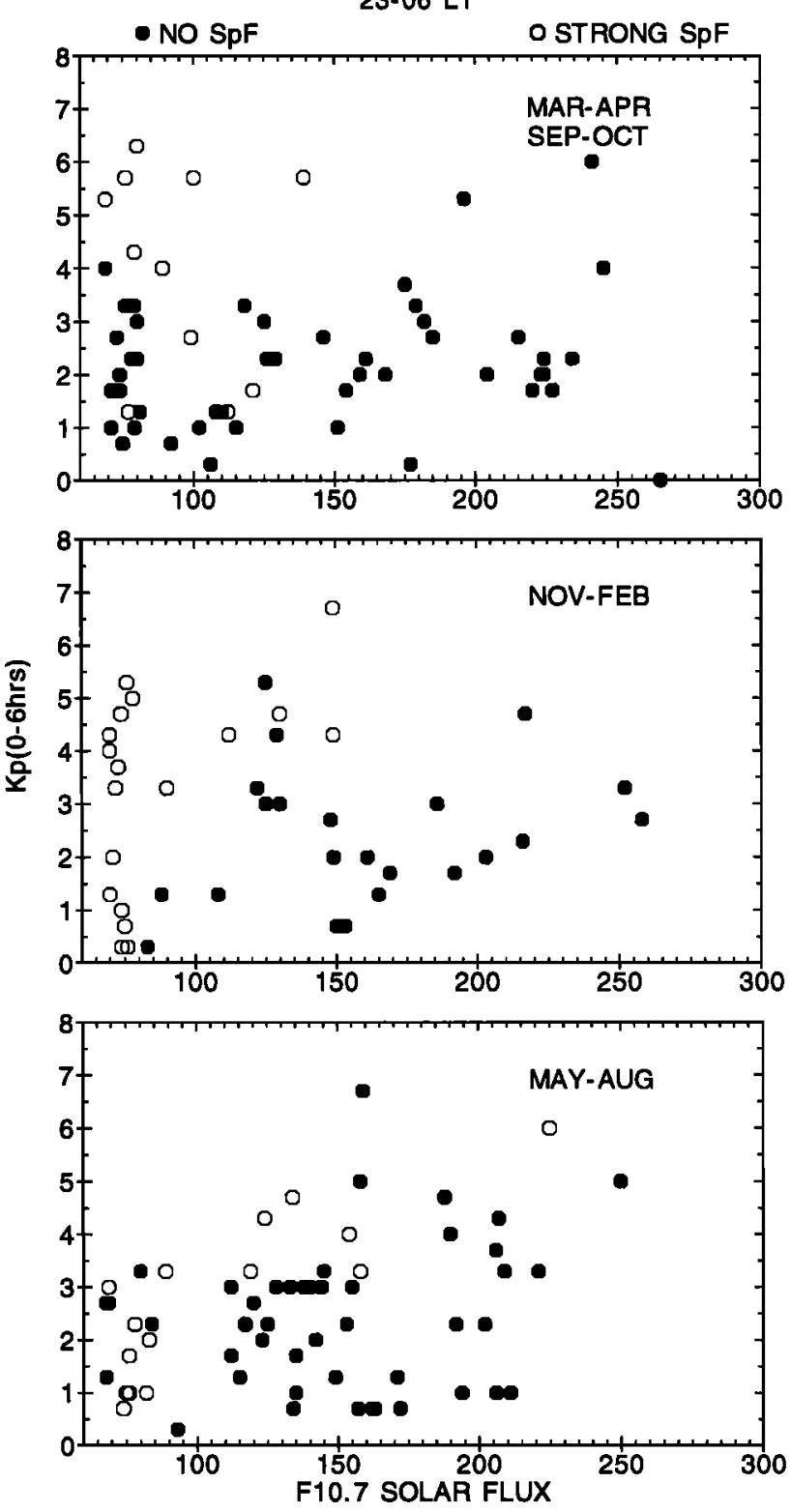

Figure 11. Plot of seasonal, solar cycle, and magnetic activity effects on late night spread $F$.

We have seen that for a given phase of the solar cycle, the effect of magnetic activity on the occurrence of spread $F$ is strongly dependent on the undisturbed downward plasma drifts which need to be overcome for the onset of the instability. Several studies have shown that the equatorial vertical drifts vary significantly with longitude [e.g., Scherliess and Fejer, 1999]. In the evening sector, it is likely that the ionospheric disturbance dynamo drifts are also longitude dependent. These effects could explain the longitudinal variation on the geomagnetic control of $F$ region irregularities which can be inferred from the scintillation data presented by Aarons et al. [1980].

\subsection{Other Processes}

Several studies have suggested that the seasonal and longitudinal dependence of these irregularities can be explained by field line integrated conductivity effects due to
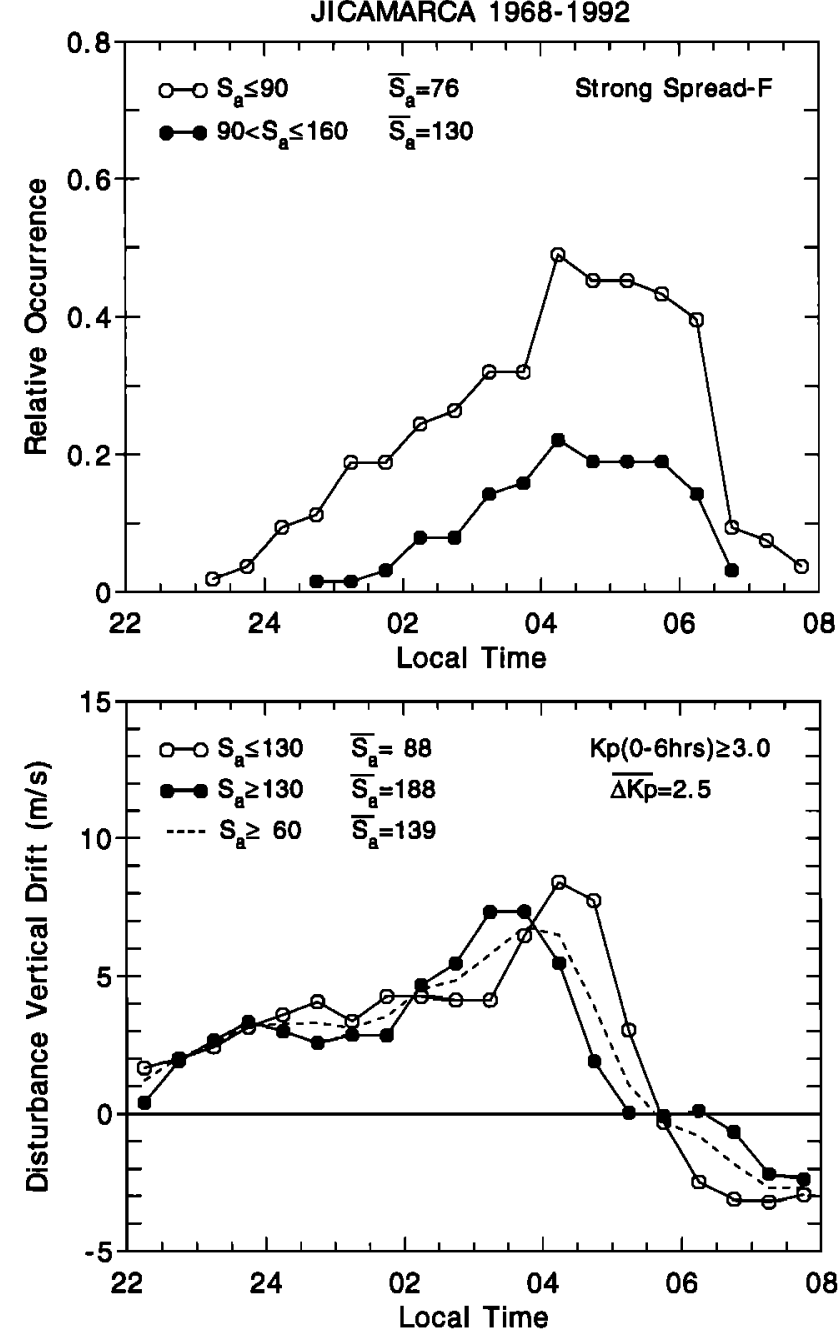

Figure 12. Local time variation of the frequency of occurrence of late night spread $F$ and of the amplitude of disturbance dynamo plasma drifts for three solar flux ranges.

magnetic declination and transequatorial meridional neutral winds [e.g., Maruyama and Matuura, 1984; Tsunoda, 1985; Maruyama, 1988; Mendillo et al., 1992]. These processes, which directly decrease the growth of the Rayleigh-Taylor instability, certainly affect the critical upward velocities and layer heights necessary for the generation of spread $F$. It is important to note, however, that the prereversal enhancement of the vertical ExB drift velocity is determined by the effects of the $E$ and $F$ region zonal winds and the longitudinal gradient of the magnetic field line integrated Pedersen conductivity across the terminator. Therefore, since magnetic declination and transequatorial meridional winds change the longitudinal (westward) gradient of the field line integrated Pedersen conductivity across the dusk terminator, they also directly affect the evening vertical drift velocities. On the other hand, large changes in the prereversal velocity enhancement can also occur in the absence of significant changes in the transequatorial neutral wind pattern due to sporadic $E$ layers, variability of the zonal winds, or to disturbance dynamo and prompt penetration electric fields. Sastri et al. [1997] described range spread $F$ events over Fortaleza during June solstice (when these irregularities are rarely observed over this station), which were associated with unusually large 
prereversal velocity enhancements without changes in the meridional wind pattern prior to the onset of spread $F$.

In this study, we have focused on the relationship of vertical plasma drifts and spread $F$, and pointed out that our results can be explained without invoking seeding mechanisms which always appear to be present. The possible importance of bottomside seed perturbations was suggested by simulations studies and was also proposed as an explanation for the occurrence of large scale wavelike spread $F$ structures. Recently, McClure et al. [1998] presented a very detailed study of the seasonal and longitudinal variation of equatorial $F$ region irregularities based on measurements from the AE-E satellite. They explained the measured seasonal and longitudinal variations of $F$ region irregularity occurrence as due to the corresponding variations in probability patterns of the seeding by thermospheric gravity waves driven by tropospheric convection near the dip equator. Although our 3$\mathrm{m}$ wave measurements cannot be directly related to these satellite observations, we believe that the seasonal and longitudinal variations of the vertical plasma drift and field line integrated conductivity patterns need to be fully accounted for in determining the possible effects of seeding mechanisms. Gravity waves must certainly play a role in the spatial and temporal characteristics of the large scale spread $F$ structures, but we have no evidence that they can account for the full range of results which can easily be explained as due to the vertical plasma drift velocity.

Sekar and Kelley [1998] and Basu and Coppi [1999] have examined the effects of zonal electric fields and of vertical shears in the zonal plasma drift velocity on equatorial spread $F$. Sekar and Kelley [1998] pointed out that the variability in occurrence characteristics of these irregularities depend on the variability in the prereversal enhancement of the vertical plasma drift velocity, which is consistent with the results of this study.

\section{Conclusions}

We have seen that the vertical plasma drifts play a dominant role on the generation and evolution of 3-m equatorial spread $F$ irregularities over Jicamarca. The dependence of these irregularities on local time, season, solar cycle, and magnetic activity can be largely explained by corresponding effects on the evening and nighttime vertical drifts.

In the evening sector, when the upward drifts are larger than $-5-10 \mathrm{~m} / \mathrm{s}$ near solar minimum, narrow unstable layers of weak irregularities are generated in the lower $F$ region in all seasons. The motion of these bottomtype irregularities is dominated by $E$ region dynamo electric fields. For upward drift velocities larger than $\sim 15-20 \mathrm{~m} / \mathrm{s}$, the unstable layer is lifted to altitudes where the gravitational drift term is dominant in the growth rate of the Rayleigh-Taylor instability leading to wide and strong scattering regions, which often give rise to radar plumes extending into the topside ionosphere. These irregularities move under the effects of $F$ region dynamo and polarization electric fields. The upward drift velocities and layer heights necessary for the generation of spread $F$ increase with solar activity. For a decimetric solar flux index of 200 , for example, peak upward drift velocities of $\sim 40-45 \mathrm{~m} / \mathrm{s}$ are required for the generation of strong spread $F$. In this case, strong irregularities are observed most often and have longest lifetimes during December solstice when the late reversal time and the small early night downward drifts are particularly favorable for the development of strong scattering layers and are rare during June solstice when the upward drifts are small, the drift reversal occurs early, and the downward drifts are very large. In the late night sector, spread $F$ is often observed near solar minimum when the small downward plasma drifts can easily be reversed, but are rarely observed during high solar flux quiet time periods due to the large downward plasma drifts. Spread $F$ irregularities are sometimes observed throughout the night over Jicamarca mostly during solar minimum.

The effect of magnetic activity on equatorial spread $F$ can easily be accounted for by considering the response of the vertical plasma drifts to high latitude current disturbances. In the evening sector, prompt penetration eastward (westward) electric fields associated with large and sudden increases (decreases) in the high-latitude convection increase (decrease) the upward drift velocities and therefore the probability of occurrence of spread $F$. Disturbance dynamo electric fields are westward near dusk and therefore they inhibit the generation of irregularities particularly during equinox solar maximum conditions when they have largest amplitudes. The polarities of the prompt penetration and disturbance dynamo electric fields are reversed in the late night sector, and their magnitudes do not change much with solar flux. In this case, the most favorable conditions for the generation of irregularities occur following large and sudden decreases in convection when both the prompt penetration and the disturbance dynamo electric fields drive late night upward plasma drifts with largest amplitudes at $\sim 0400$ local time. These disturbance drifts can easily overcome the small ambient quiet time downward drifts near solar minimum. For higher solar flux conditions, however, increasingly larger disturbance drifts are required for the generation of late night spread $F$ as a result of the large increase of the nighttime downward drift velocity from solar minimum to solar maximum. Our results suggest that the geomagnetic control of spread $F$ varies with season, solar cycle, and longitude due to corresponding changes in the quiet and disturbance drift patterns.

Acknowledgments. We thank the Jicamarca staff for carrying out these measurements over the last three decades, and D. Hysell for several important comments. This work was supported by the Aeronomy Program, Division of Atmospheric Sciences of the National Science Foundation through grants ATM-9613953, ATM-9731704, and ATM9714677 to Utah State University. E. R. de Paula was supported by the Fundaçaõ de Amparo a Pesquisa do Estado de Saõ Paulo (FAPESP) under process 98/02010-1. The Jicamarca Radio Observatory is operated by the Instituto Geofisico del Peru with support from the National Science Foundation.

Janet G. Luhmann thanks Mangalathayil Ali Abdu and Sidney L. Ossakow for their assistance in evaluating this paper.

\section{References}

Aarons, J., The role of the ring current in the generation and inhibition of equatorial $\mathrm{F}$ layer irregularities during magnetic storms, Radio Sci., 26, 1131-1149, 1991.

Aarons, J., J. P. Mullen, J. P. Koster, R. F. da Silva, J. R. Medeiros, R. T. Medeiros, A. Busby, J. Pantoja, J. Lanat, and M. R. Paulson, Seasonal and geomagnetic control of equatorial scintillations in two longitudinal sectors, J. Atmos. Terr. Phys., 42, 861-866, 1980.

Abdu, M. A., R. T. Medeiros, J. A. Bittencourt, and I. S. Batista, Vertical ionization drift velocities and range type spread $F$ in the evening equatorial ionosphere, J. Geophys. Res., 88, 399-402, 1983.

Abdu, M. A., I. S. Batista, G. O. Walker, J. H. A. Sobral, N. B. Trivedi, and E. R. de Paula, Equatorial ionospheric electric fields during magnetospheric disturbances: Local time/ longitudinal dependencies from recent EITS campaigns, J. Atmos. Terr. Phys., 57, 1065-1083, 1995. 
Basu, B., and B. Coppi, Relevance of plasma and neutral wind profiles to the topology and the excitation of modes for the onset of equatorial spread F, J. Geophys. Res., 104, 225-231, 1999.

Basu, Su., S. Basu, J. P. Mullen, and A. Bushby, Long-term $1.5 \mathrm{Ghz}$ amplitude scintillation measurements at the magnetic equator, Geophys. Res. Lett., 4, 259-262, 1980.

Basu, S., et al., Scintillations, plasma drifts, and neutral winds in the equatorial ionosphere after sunset, J. Geophys. Res., 101, 26795$26809,1996$.

Booker, H., and H. W. Wells, Scattering of radio waves in the $F$ region of the ionosphere, J. Geophys. Res., 43, 249-256, 1938.

Farley, D. T., Radio wave scattering from the ionosphere, in Methods of Experimental Physics, Vol. 9B, Plasma Physics, edited by R. H. Lovberg and H. R. Griem, pp. 139-186, Academic, San Diego, Calif., 1971.

Farley, D. T., and D. L. Hysell, Radar measurements of very small aspect angles in the equatorial ionosphere, J. Geophys. Res., 101 $5177-5184,1996$.

Farley, D. T., B. B. Balsley, R. F. Woodman, and J. P. McClure, Equatorial spread $F$ : Implications of VHF radar observations, $J$. Geophys. Res., 75, 7199-7216, 1970.

Fejer, B. G., The equatorial ionospheric electric fields. A review, $J$. Atmos. Terr. Phys., 43, 377-386, 1981.

Fejer, B. G., Low latitude electrodynamic plasma drifts: A review, $J$. Atmos. Terr. Phys., 53, 677-693, 1991

Fejer, B. G., Natural ionospheric plasma waves, in Modern lonospheric Science, edited by H. Kohl, R. Rüster, and K. Schelegel, pp. 217273, Max-Planck Ins. für Aeron., Lindau, Germany, 1996.

Fejer, B. G., The electrodynamics of the low-latitude ionosphere: Recent results and future challenges, J. Atmos. Sol. Terr. Phys., 59, 1456-1482, 1997.

Fejer, B. G., and M. C. Kelley, Ionospheric irregularities, Rev. Geophys., 18, 401-450, 1980

Fejer, B. G., and L. Scherliess, Empirical models of storm time equatorial zonal electric fields J. Geophys. Res., 102, 24047-24056, 1997.

Fejer, B. G., D. T. Farley, B. B. Balsley, and R. F. Woodman, Radar studies of anomalous velocity reversals in the equatorial ionosphere, J. Geophys. Res., 81, 4621-4626, 1976.

Haerendel, G., Theory of equatorial spread $F$, report, Max-PlanckInstit. für extraterre. Phys., Garching, Germany, 1973.

Hanson, W. B., B. L. Cragin, and A. Dennis, The effects of the vertical drift on the equatorial $F$ region stability, J. Atmos. Terr. Phys., 48 , 205-212, 1986.

Hysell, D. L., and J. D. Burcham, JULIA radar studies of equatorial spread F, J. Geophys. Res., 103, 29155-29167, 1998.

Hysell, D. L., and R. F. Woodman, Imaging coherent backscatter radar observations of the topside equatorial $F$ region, Radio $S c i$., 32, 2309 2320, 1997.

Hysell, D. L., M. C. Kelley, W. E. Swartz, and R. F. Woodman, Seeding and layering of equatorial spread $F$ by gravity waves, $J$. Geophys. Res., 95, 17253-17260, 1990.

Jayachandran, B., N. Balan, P. B. Rao, J. H. Sastri, and G. J. Bailey, HF Doppler and ionosonde observations on the onset conditions of equatorial spread $F, J$. Geophys. Res., 98, 13741-13750, 1993.

Kelley, M. C., The Earth's Ionosphere: Plasma Physics and Electrodynamics, Int. Geophys. Ser., vol. 43, Academic, San Diego, Calif., 1989.

Kelley, M. C., and T. Maruyama, A diagnostic method for equatorial spread $F, 2$, The effect of magnetic activity, J. Geophys. Res., 97 1271-1277, 1992.

Kelley, M. C., et al., The Condor equatorial spread $F$ campaign: Overview and results of the large scale measurements, J. Geophys. Res., 91, 5487-5503, 1986.

Keskinen, M. J., S. L. Ossakow, S. Basu, and P. J. Sultan, Magnetic-fluxtube-integrated evolution of equatorial plasma bubbles, J. Geophys. Res., 103, 3957-3967, 1998.

Kudeki, E., and S. Bhattacharyya, Post sunset vortices in equatorial $F$ region plasma drifts and implications for bottomside spread $F, J$. Geophys. Res., in press, 1999.

Kudeki, E., S. Bhattacharyya, and R. F. Woodman, A new approach in incoherent scatter $F$ region ExB drift measurements at the Jicamarca Radio Observatory, J. Geophys. Res., in press, 1999.

Lyon, A. J., N. J. Skinner, and R. W. Wright, Equatorial spread $F$ at Ibadan, Nigeria, J. Atmos. Terr. Phys., 21, 743-756, 1961.
MacDougall, J. W., M. A. Abdu, P. T. Jayachandran, J.-F. Cecile, and I. S. Batista, Presunrise spread $F$ at Fortaleza, J. Geophys. Res., 103, 23415-23425, 1998.

Maruyama, T., A diagnostic model for equatorial spread $F$ 1. Model description and applications to electric field and neutral wind effects, J. Geophys. Res., 93, 14611-14622, 1988.

Maruyama, T., and N. Matuura, Longitudinal variability of annual changes in activity of equatorial spread $F$ and plasma depletions, $J$. Geophys. Res., 89, 10903-10912, 1984.

McClure, J. P., S. Singh, D. K. Bamgboye, F. S. Johnson, and H. Kil, Occurrence of equatorial $F$ region irregularities: Evidence for tropospheric seeding, J. Geophys. Res., 103, 29119-29135, 1998.

Mendillo, M., J. Baumgardner, X.-Q. Pi, P. J. Sultan, and R. T. Tsunoda, Onset conditions for equatorial spread-F, J. Geophys. Res., 97, 13865-13875, 1992.

Ossakow, S. L., Spread-F theories - A review, J. Atmos. Terr. Phys., 43, 437-452, 1981.

Ossakow, S. L., S. T. Zalesak, B. E. McDonald, and P. K. Chaturvedi, Nonlinear equatorial spread $F$ : Dependence on altitude of the $F$ peak and bottomside background electron density gradient length, $J$. Geophys. Res., 84, 17-29, 1979.

Rastogi, R. M., Seasonal and solar cycle variations of equatorial spread$F$ in the American sector, J. Atmos. Terr. Phys., 42, 593-597, 1980.

Rastogi, R. G., and J. Aarons, Nighttime ionospheric radio scintillations and vertical drifts at the magnetic equator, J. Atmos. Terr. Phys. 42 , 583-591, 1980.

Rastogi, R. M., J. P. Mullen, and E. MacKenzie, Effect of geomagnetic activity on equatorial radio VHF scintillations and spread $F, J$. Geophys. Res., 86, 3661-3664, 1981.

Sahai, Y., P. R. Fagundes, J. A. Bittencourt, and M. A. Abdu, Occurrence of large scale equatorial $F$-region depletions during geo-magnetic disturbances, J. Atmos. Sol. Terr. Phys., 60, 15931604, 1998.

Sastri, J. H., Duration of equatorial spread F, Ann. Geophys., 2, 353358,1984 .

Sastri, J. H., M. A. Abdu, I. S. Batista, and J. H. A. Sobral, Onset conditions of equatorial (range) spread $F$ at Fortaleza, Brazil, during the June solstice, J. Geophys. Res., 102, 24013-24021, 1997.

Scannapieco, A. J., and S. L. Ossakow, Nonlinear equatorial spread $F$, Geophys. Res. Lett., 3, 451-454, 1976.

Scherliess, L., and B. G. Fejer, Storm time dependence of equatorial disturbance dynamo zonal electric fields, J. Geophys. Res., 102, 24037-24046, 1997.

Scherliess, L., and B. G. Fejer, Radar and satellite global equatorial $F$ region vertical drift model, J. Geophys. Res., 104, 6829-6842, 1999.

Sekar, R., and M. C. Kelley, On the combined effects of vertical shear and zonal electric field patterns on nonlinear equatorial spread $F$ evolution, J. Geophys. Res., 103, 20735-20747, 1998.

Sobral, J. H. A., M. A. Abdu, W. D. Gonzalez, B. T. Tsurutani, I. S. Batista, and A. L. Clua de Gonzalez, Effects of intense storms and substorms on the equatorial ionosphere/thermosphere system in the American sector from ground-based and satellite data, J. Geophys. Res., 102, 14305-14313, 1997.

Sultan, P. J., Linear theory and modeling of the Rayleigh-Taylor instability leading to the occurrence of equatorial spread $F, J$. Geophys. Res., 101, 26875-26891, 1996.

Tsunoda, R. T., Control of the seasonal and longitudinal occurrence of equatorial scintillations by the longitudinal gradient in integrated $F$ region Pedersen conductivity, J. Geophys. Res., 90, 447-456, 1985.

Woodman, R. F., Vertical drift velocities and east-west electric fields at the magnetic equator, J. Geophys. Res., 75, 6249, 1970.

Woodman, R. F., and C. LaHoz, Radar observations of $F$ region equatorial irregularities, J. Geophys. Res., 81, 5447-5466, 1976.

Zalesak, S. T., S. L. Ossakow, and P. K. Chaturvedi, Nonlinear equatorial spread $F$ : The effect of neutral wind and background Pedersen conductivity, J. Geophys. Res., 87, 151-166, 1982.

B. G. Fejer and L. Scherliess, Center for Atmospheric and Space Sciences, Utah State University, Logan, UT 84322-4405. (bfejer@cc.usu.edu)

E. R. de Paula, Instituto Nacional de Pesquisas Espaciais, Saõ José dos Campos, Sao Paulo, Brazil.

(Received April 23, 1999; revised June 14, 1999; accepted June 14, 1999.) 